\title{
The effects of ageing on differentiation and characterisation of human mesenchymal stem cells
}

\section{Running title: Ageing in mesenchymal stem cells}

Authors: Hiba Khan (1), Pouya Mafi (2), Reza Mafi (2), Wasim Khan (3)

1. Hull York Medical School, Cottingham Road, Hull, HU6 7RX, UK

2. Nuffield Department of Orthopaedics, Rheumatology and Musculoskeletal Sciences, University of Oxford, Oxford, OX3 7LD, UK

3. Division of Trauma and Orthopaedics, University of Cambridge, Addenbrooke's Hospital, Cambridge, CB2 2QQ, UK

\section{Corresponding Author}

Wasim Khan PhD, FRCS(Tr\&Orth), Clinical Lecturer and Consultant Orthopaedic Surgeon, University of Cambridge, Addenbrooke's Hospital, Cambridge, CB2 0QQ, UK

Tel: +44 (0) 7791025554

E-mail: wasimkhan@ doctors.org.uk 


\begin{abstract}
:
Background: Mesenchymal stem cells (MSC) are unique in their ability to self-renew and differentiate into one of many lineage possibilities. It is therefore integral to preserve these qualities to prevent the far reaching effects of a defective stem cell. Human mesenchymal stem cells (hMSC) are precursors for and can differentiate into osteoblasts, adipocytes and chondrocytes. They were originally found in the bone marrow, but have also been located in the umbilical cord, adipose tissue and muscle. Few studies have been conducted into the in vivo effects of age on these cells. This contribution reviews current knowledge surrounding the effects of age on the characterisation and differentiation of human mesenchymal stem cells.
\end{abstract}

Methods: 471 articles were found using a combination of Online published articles from January 1983 to January 2016 were searched using the Cochrane Library, PubMed, Medline, Scopus, Web of Science and Science Direct databases. There were no existing systematic reviews on this research topic.

Results: Nine studies were identified that met the predefined selection criteria. Three studies were used to assess the effects of ageing on characterisation of hMSC with no conclusive results. The cumulative results of these studies show that the effect of ageing on characterisation of hMSC remains inconclusive. Seven studies were used to assess the differentiation potentials of hMSC showing that age either decreased or altered lineage preference in hMSC differentiation.

Conclusion: There is indication that ageing affects hMSC characterisation and differentiation, however it is not conclusive. There are not enough high quality controlled clinical trials to make reliable conclusions.

Keywords: age, characterisation, differentiation, human mesenchymal stem cells, proliferation, systematic review

The effects of age on human cells has long been an area of scientific interest as well as of significant importance to the general population. In particular, mesenchymal cells have been identified as key progenitor cells affected by the ageing process. Bone marrow derived stem cells for non-haematopoietic tissues are generally known as mesenchymal stem cells (MSC) [1]. Mesenchymal stem cells (hMSC) are characterised as being plastic adherent, non-hematopoietic cells that reside in a perivascular niche in the bone marrow stroma, that possess self-regeneration and multi-lineage differentiation capacity[2,3].

hMSC are known to be found in the bone marrow, but are also present in umbilical cord blood, placenta, foetal liver, lung, corneal stroma, adult muscle and deciduous infant teeth [4,5]. The accuracy of the term "mesenchymal" has been disputed as it should encompass both blood and connective tissue lineages[6], 
however, they only produce connective tissue cells. In addition, there have been different names ascribed to hMSC such as skeletal or stromal stem cells (SSC); but for the purpose of this review the term mesenchymal stem cell (MSC) will be used [7].

The difference between the mesenchymal and haematopoetic stem cell lineages are shown in (Figure 1). Both cells exist in the bone marrow where they differentiate to follow their lineage progression through intermediate progenitors to terminally differentiated cells such as osteoblasts, adipocytes and chrondrocytes. In addition, some hMSC are hypothesized to become non-adherent osteoprogenitor cells which can be mobilised for distal bone growth or fracture repair[8] .

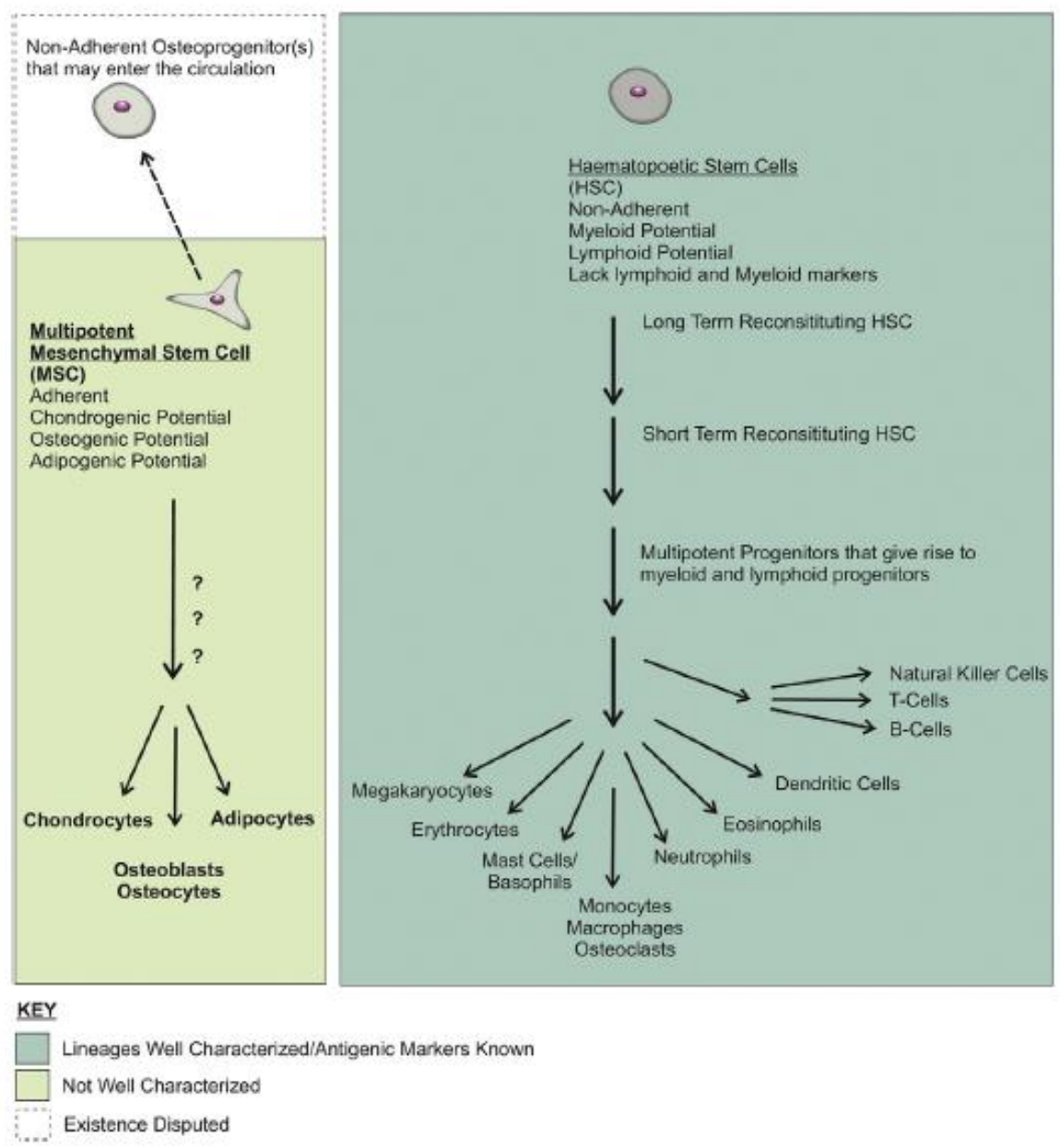

Figure 1 The lineage differentiation of mesenchymal and haematopoietic stem cells [8].

The characterisation criteria of mesenchymal stem cells have been standardised by The International Society for Cellular Therapy (ISCT) who outline the following criteria for the characterisation of hMSC: (1) adherence to plastic; (2) differentiation into chondrocytes, osteoblasts, and adipocytes under standard in vitro differentiating conditions; and (3) expression of surface markers CD105, CD73, and CD90, in the absence of haematopoietic markers CD45, CD34, CD14, CD11b, CD79 $\alpha$, CD19, and HLA-DR. The criteria are not ideal for in vivo models, though they are apt for in vitro experimentation $[9,10]$.

Research has shown that MSCs form into their specific descendants due to lineage specific transcription factors. Differentiation into osteoblasts requires Runt-related transcription factor-2 and Osterix which regulate osteogenesis and some cartilage formation. Whereas differentiation into adipocytes requires the presence of the nuclear hormone receptor transcription factor Peroxisome proliferator-activated receptor- $\gamma(\operatorname{PPAR} \gamma)$ and the CAAT/enhancer binding protein- $\alpha(\mathrm{C} / \mathrm{EBP} \alpha)$. The chondrocyte is transcribed by the presence of SRY-box containing gene 9 (SOX9) [11].

Studies of the ageing process of hMSC indicate three types of aging modifications seen in hMSC: (1) changes in quantity, (2) changes in quality (differentiation/regeneration capacity) and (3) changed mobilization capacity 
[8]. Further subdivisions can be made into MSC types by how they are affected by the ageing process as compared to somatic cells. This is based on the following characteristics (Table 1): differentiation potential, abilitiy to senesce, telomerase activity and self renewal. These types are known as the deteriorating MSC, the persistent MSC and the rarer perennial MSC which is able to avoid the ageing process altogether. The formation of the subdivisional types is dependent on external factors such as oxidative stress, genetic aberration and the quantity of transcriptional stimuli. The accumulation of aged hMSC then cause compromise of tissues and organs due to their diminishing ability to create more progeny $[12,13,14]$.

\begin{tabular}{|l|l|l|l|l|}
\hline & Somatic Cells & Deteriorating MSC & Persistent MSC & Perennial MSc \\
\hline $\begin{array}{l}\text { Differentiation } \\
\text { potential }\end{array}$ & None & Some & Some & Great \\
\hline Senescence & Yes & Yes & Yes & No \\
\hline Telomerase & Inactive & Inactive & Potential & Active \\
\hline Self-Renewal & No & No & Yes & Yes \\
\hline Examples & $\begin{array}{l}\text { Sozou and } \\
\text { Kirkwood (2001) }\end{array}$ & $\begin{array}{l}\text { Simonsen et al. } \\
(2002) \text { and } \\
\text { Stenderup et al. } \\
(2003)\end{array}$ & $\begin{array}{l}\text { Pittenger et al. } \\
(1999) \text { and } \\
\text { Schieker et al. } \\
(2004)\end{array}$ & $\begin{array}{l}\text { Jiang et al. (2002) } \\
\text { and Yoon et al. } \\
(2005)\end{array}$ \\
\hline
\end{tabular}

Table 1 Hypothetical classification of age behaviour of different subsets in adult stem cells. $[15,16,17,18,19,20,21,22]$

However, it is not known whether the ageing of MSCs is caused by intrinsic or external factors [23,24]. Reduced proliferation of hMSC could be caused by intrinsic factors such as hMSC with markers for senescenceassociated b-galactosidase increased expression of p53 and its genes (p21 and BAX). Whereas external factors could be reduced synthesis of proteoglycans, glycosaminoglycans and reactive oxygen species which compromise cell viability and have the ability to trigger apoptosis [25,26, 27].

\section{Method}

This systematic review followed the PRISMA guidelines with the following pathway outcomes.

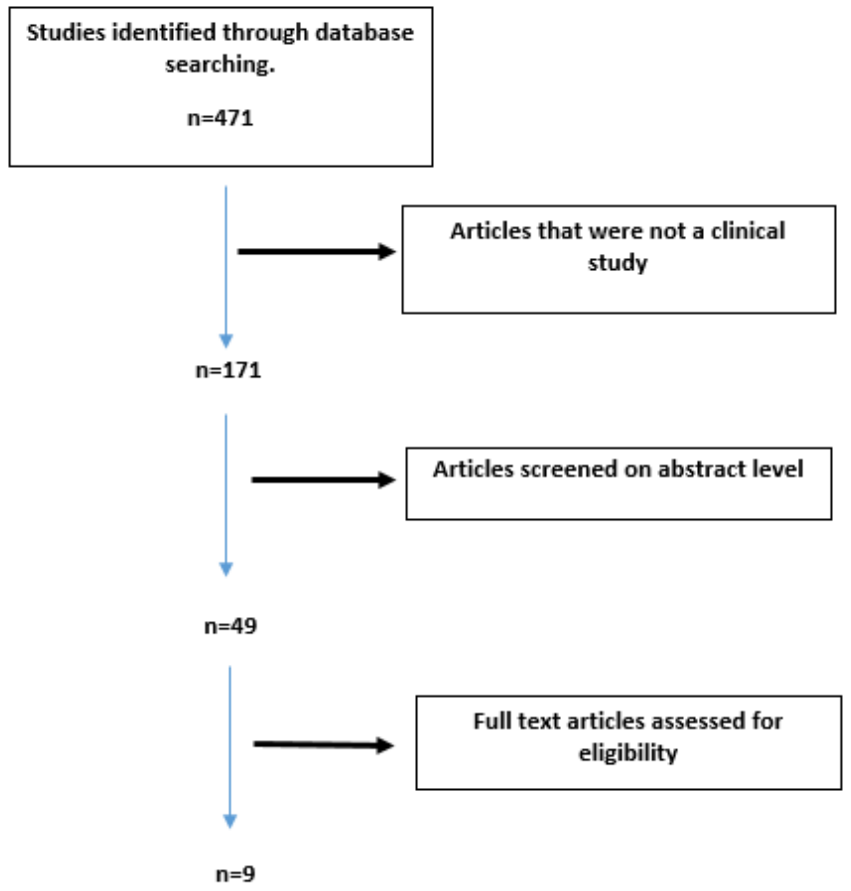


Figure 2 - Search pathway for review.

\section{Search}

Online published articles from January 1983 to January 2016 were searched using the Cochrane Library, PubMed, Medline, Scopus, Web of Science and Science Direct databases. The initial literature search in Cochrane yielded 0 results. Instead, we used MeSH-terms (Medical Subject Headings, controlled vocabulary thesaurus used for indexing articles) in the other databases: "Ageing”[Mesh] AND "human mesenchymal stem cells"[Mesh]; "Ageing” AND "Characterisation and Differentiation"[Mesh] AND "human mesenchymal stem cells,"[Mesh]. Limits were set for: "language English," "humans," and "full text available," There were no existing systematic reviews on this research topic. Unpublished studies were searched for in the clinical trial registries and a hand search was conducted of additional articles using the same search terms as mentioned above.

\section{Selection Criteria}

Studies were selected based on the following inclusion criteria: (1) original research papers with prospective or retrospective design (double- blind, placebo-controlled or randomized controlled trials [RCTs], observational studies, population-based studies, cohort studies), (2) studies used the International Society for Cellular Therapy (ISCT) characterisation criteria 3) English language, (4) carried out in humans, (5) published in an peerreviewed journal, and (6) full text available.

Studies were excluded in case of: (1) not using ISCT criteria for characterisation.

\section{Results}

471 articles were identified and of those nine studies were selected through the inclusion and exclusion criteria. Both the effects of ageing on the 1) Characterisation of mesenchymal stem cells and 2) Differentiation of mesenchymal stem cells were highlighted as focus areas. All studies are shown in Table 2 below:

\begin{tabular}{|c|c|c|c|c|c|c|}
\hline Study & $\begin{array}{l}\text { Number of } \\
\text { participants }\end{array}$ & $\begin{array}{l}\text { Altered } \\
\text { adherence } \\
\text { to plastic } \\
\text { according } \\
\text { to age }\end{array}$ & $\begin{array}{l}\text { Lineage } \\
\text { differentiation }\end{array}$ & $\begin{array}{l}\text { Expression } \\
\text { of surface } \\
\text { markers }\end{array}$ & $\begin{array}{l}\text { Population } \\
\text { doublings }\end{array}$ & $\begin{array}{l}\text { Colony } \\
\text { forming } \\
\text { units } \\
\text { (CFU) }\end{array}$ \\
\hline $\begin{array}{l}\text { Choudery } \\
\text { et al. }\end{array}$ & 29 & No & Varied & stable & Decrease & $\begin{array}{l}\text { fewer, } \\
\text { smaller }\end{array}$ \\
\hline Feng et al & 33 & N/A & Decreased & N/A & Decrease & N/A \\
\hline $\begin{array}{l}\text { Aksoy et } \\
\text { al }\end{array}$ & 29 & no & Decreased & stable & Decrease & $\mathrm{n} / \mathrm{a}$ \\
\hline $\begin{array}{l}\text { Fossett et } \\
\text { al }\end{array}$ & 14 & $\mathrm{n} / \mathrm{a}$ & $\mathrm{n} / \mathrm{a}$ & decrease & $\begin{array}{l}\text { not } \\
\text { significant }\end{array}$ & $\mathrm{n} / \mathrm{a}$ \\
\hline $\begin{array}{l}\text { D'Ippolito } \\
\text { et al }\end{array}$ & 41 & $\mathrm{n} / \mathrm{a}$ & Decreased & $\mathrm{n} / \mathrm{a}$ & Decrease & $\mathrm{n} / \mathrm{a}$ \\
\hline Zaim et al & 18 & $\mathrm{n} / \mathrm{a}$ & Varied & $\mathrm{n} / \mathrm{a}$ & Decrease & $\mathrm{n} / \mathrm{a}$ \\
\hline $\begin{array}{l}\text { Mendez et } \\
\text { al }\end{array}$ & 12 & $\mathrm{n} / \mathrm{a}$ & Decreased & $\mathrm{n} / \mathrm{a}$ & Decrease & $\mathrm{n} / \mathrm{a}$ \\
\hline $\begin{array}{l}\text { Justesen et } \\
\text { al }\end{array}$ & 34 & $\mathrm{n} / \mathrm{a}$ & $\begin{array}{l}\text { Remained } \\
\text { stable }\end{array}$ & $\mathrm{n} / \mathrm{a}$ & $\mathrm{n} / \mathrm{a}$ & $\mathrm{n} / \mathrm{a}$ \\
\hline $\begin{array}{l}\text { Stolzing et } \\
\text { al }\end{array}$ & 33 & $\mathrm{n} / \mathrm{a}$ & Varied & Decrease & Decrease & $\begin{array}{l}\text { fewer, } \\
\text { smaller }\end{array}$ \\
\hline
\end{tabular}

Table 2 - Table of included key studies in this review [28,29,30,31,32,33,34,35,36].

\section{Effects of ageing on the characterisation of mesenchymal stem cells}

Three studies were eligible in assessing the effect of ageing on characterisation of hMSC based on being able to contribute to at least two out of three of the International Society for Cellular Therapy (ISCT) characterisation criteria: 
(1) adherence to plastic; (2) differentiation into chondrocytes, osteoblasts, and adipocytes under standard in vitro differentiating conditions; and (3) expression of surface markers CD105, CD73, and CD90, in the absence of haematopoetic markers CD45, CD34, CD14, CD11b, CD79 $\alpha$, CD19, and HLA-DR.

Sample size varied from 29 to 33 participants and all three were cross sectional.

Choudhery found there to be no difference in finding the three characterisation criteria in all age groups. The study of 29 participants were divided into three categories; <30, 35-55 and >60. The mean age for the <30 category was 25.5 and child donors did not participate. All hMSC displayed identical characteristics, those being plastic adherent growth, differentiation into chondrocytes, osteoblasts, and adipocytes under standard in vitro differentiating conditions; and (3) expression of surface markers. CD14, CD19, that aged hMSC can be characterised by the presence of greater mRNA levels of the tumour suppressor gene p16 and apoptosis inducing gene $\mathrm{p} 21(\mathrm{p}<0.05)$. In addition, higher levels of the marker senescence-associated b-galactosidase and lower levels of super oxidase dismutase, an antioxidant that counteracts the actions of reactive oxygen species were found to be indicators of aging. There was no variability in expression of surface markers with age and hMSC were positive for the characterisation requirement MSC markers (CD44, CD73, CD90, CD105) but lack expression of hematopoietic markers (CD3, CD14, CD19, CD34,CD45). The study also showed that the number of cells per gram and colony forming units as well as cell doublings per unit time decreased with MSC and donor age $(\mathrm{p}<0.01)[28]$.

Stolzing found an age-related reduction in the expression of MSC cell surface markers CD90, CD105, and STRO-1, and an increase in CD44 as well as a varied differentiation potential with age. Bone marrow hMSC were obtained for the study by aspiration through the posterior iliac crest of all donors [36]. The age range of the 33 donors was between 5-55 years. However, Fosset measured cell surface characterisation of hMSC of different donor ages and found no age related changes in cell surface marker expression [31].

Aksoy's results showed no significant change in plastic adherence with older hMSC, lineage differentiation capacity decreased and expression of surface markers was found to have been present on cells of all ages. The presence of surface markers CD105, CD90, CD73, CD45, and CD34 were present on all hMSC. These results were yielded from the bone marrow hMSC of five different age groups of similar sample sizes: infants(0-3 years of age, $n=6$ ), children (ages $>3-12$ years, $n=6$ ), adolescents (ages $>12-19$ years, $n=6$ ), early adults (ages $>19-35$ years, $n=6$ ), and mid adults (ages $>35-50$ years, $n=5$ ). They also found that hMSC isolated from younger donors, had higher cellular metabolic activity and proliferation rate than older donor cells [30].

\section{Effects of ageing on the proliferation of mesenchymal stem cells}

Seven studies confirmed a decrease in proliferation of hMSC in relation to age.[28, 31, 33]. Fosset and Zaim all yielded a $\mathrm{p}$ value $<0.05$ when comparing age to population doubling whereas, Zaim produced a $\mathrm{p}$ value of $<$ 0.001. All other seven studies remarked on a clear decrease in MSC proliferation with age.

\section{Effects of ageing on the differentiation of mesenchymal stem cells}

Eight eligible studies were identified to assess the effects of ageing on the differentiation of mesenchymal stem cells. Sample sizes ranged from $12-41$ participants.

Of the eight studies, two showed a decreased osteogenic potential coupled with an increased adipogenic preference incurring with aged cells. [28] and [36] found there to be decreased osteogenic differentiation in favour of increased adipogenic differentiation in older donor hMSC.

Stolzing found that 'stressing' cells with $\mathrm{H} 2 \mathrm{O} 2$ to mimic reactive oxygen species also lead to an overall decrease in osteogenic differentiation of hMSC, implying the effect of age on the differentiation of hMSC. This effect was also mediated by a dysfunction in receptors VDR, GR and Notch-1 which are less bioavailable as cells age. These receptors are key to the process of osteogenesis in humans. In addition, Stolzing found that adult hMSC ( $>18 \mathrm{yrs}$ ) had the same apoptosis rate as young hMSC ( $<18 \mathrm{yrs})$, however, aged hMSC (50-55 yrs) displayed significantly increased levels of apoptosis compared to the others $(p<0.001)[36]$.

Zaim compared bone marrow derived hMSC from three groups; ( $0-12$ years, $n=6)$ adult $(25-50$ years, $n=6)$ and old $(>60$ years, $n=6)$. They found slightly different results that adipogenic $(p<0.001)$ and osteogenic differentiation preference decreased with age, whereas chondrogenic potential did not change. The comparison 
between the child and adult donor chondrogenic differentiation potential was $p>0.05$ and therefore not statistically significant [33].

Four other studies showed a general decrease in differentiation potential of hMSC with age [29,30,32,34]. Feng tested dental pulp human mesenchymal cells and found that part of an ageing MSC profile was a decline in differentiation. Fourteen patients between the ages of 50- 83 years were tested in this study and they also found increased senescence-associated b-galactosidase activity in aged hMSC $(\mathrm{p}<0.05)$ and more cells occurring in the G0/G1 resting phases than in younger MSC donors [29].

\section{Discussion}

Though ageing of hMSC is a topic of interest for research, there are not enough reliable clinical studies to categorically explain the effects of ageing on hMSC. There were a high degree of heterogeneity of published studies in this systematic review. In addition, the sample size range was low at 12-41 participants which would make these conclusions preliminary.

\section{Effect of ageing on characterisation of mesenchymal stem cells}

Based on this review, the effect of ageing on characterisation of mesenchymal stem cells is that adherence to plastic is not affected by age of cells. MSC from all age groups displayed identical morphology and all exhibited appropriate adherence to plastic [28,30].

Furthermore, four out of nine studies showed decreased differentiation into osteoblasts, adipocytes or chondrocytes. However, lineage differentiation remained stable in Justenson's study and favoured the adipogenic profile over the osteogenic profile in two studies. It is hypothesized that this occurs as the body ages to reduce bone fortification as the osteogenic profile is more sensitive to reactive oxygen species which accumulate with age.

The presence of surface markers CD105, CD73, and CD90, in the absence of haematopoetic markers were CD45, CD34, CD14, CD11b, CD79 $\alpha$, CD19, and HLA-DR were seen to decrease in both Fossett and Stolzing's studies. In particular, both studies showed a consistent presence of the CD105 marker across all ages [31,36]. Fossett tested MSC derived from the synovial fat pad of 14 participants (four females, seven males) and found there to be a difference in gender. Females had a higher cell surface marker population than men $(\mathrm{p}<0.05)$. In addition, results showed strong existence of CD44, CD73 and CD105, and absence of CD45, CD54, CD80, CD90, CD106, CD166, and STRO-1, some of which are the haematopoietic markers outlined by the International Society for Cellular Therapy (ISCT) characterisation criteria.

D'Ippolito also found a decline in proliferation of MSC with age but also a loss of differentiation and multipotentiality. In this study of 41 participants, increasing age yielded both fewer and smaller colony forming units $(\mathrm{p}<0.001)[32]$.

The cumulative results of these studies show that the effect of ageing on characterisation of hMSC remains inconclusive.

\section{Effect of ageing on differentiation of mesenchymal stem cells}

Based on this review, four studies showed a decrease in lineage differentiation with age of MSC.

Studies have shown that older hMSC have a slower differentiation and proliferation rate to younger hMSC [33]. Zaim compared the proliferation rate of hMSC from children to adults and found that as donor age increased the population doubling rate of the hHMSC reduced. The incidence of morphological changes increased in cells obtained from older donors. Though this study showed statistically significant results of the osteogenic and neural differentiation potential of hMSC decreasing with donor age $(\mathrm{p}<0.001)$, the sample size was 18 and therefore less reliable.

Justesen used 34 participant samples from bone marrow aspirations from the posterior superior iliac spine. Their study found no age related effects on osteogenic or adipogenic differentiation or the associated mRNA levels, with the conclusion that aging did not alter the differentiation potential of hMSC [35]. 
The effect of age on the differentiation of hMSC to the osteogenic lineage has been most researched, and studies show that fewer osteoprogenitors are present with increasing age [37]. Three studies showed that both osteoblast differentiation and bone formation were reduced in more aged hMSC. Some studies also established that ageing causes a change in differentiation profile as well as ability to differentiate into lineages These studies found that adipocyte lineage differentiation was favoured over osteoblast differentiation in aged hMSC. It is believed that the reason for preference over adipocyte differentiation occurs due to reactive oxygen species and microRNAs that accumulate over time targeting regulatory factors Runt-2, Osterix, PPARY and C/EBP $\alpha$ [38]. However, other studies confirmed an overall reduction in differentiation to adipogenesis when compared to younger MSC donors $[39,40]$.

\section{Limitations}

The review had a number of limitations commonly associated with systematic reviews of the literature [41]. The sample size for all studies was poor with the range being $12-41$ participants. Furthermore, eight out of the nine studies did not control for gender or co-morbidities. There may also have been missed studies as the database search did not cover articles where the full text was not available.

\section{Conclusion}

In conclusion, this review suggests that there may be some evidence for the effects of ageing on decreasing or altering the differentiation potential of hMSC, however, there is no suggestive evidence on age changing key characterisation indicators such as plastic adherence and cell surface marker expression. It is important that these important questions are addressed to allow the identification of the optimal treatment for each clinical situation, and to allow stem cell applications to become more accepted in clinical practice [42-44].

It is surprising that more viable studies on the effects of ageing on the characterisation and differentiation of hMSC could not be found. Further study needs to be conducted on the effective characterisation of hMSC and more accurate investigation into the lineage differentiation of terminally differentiated cells including intermediate progenitors and external environmental factors that modulate the differentiation.

\section{Declaration of Interest Statement}

This review is independent of conflicts of interest associated with commercial sponsorship and/or affiliations.

\section{References}

[1] Caplan AI. Mesenchymal stem cells. Journal of orthopaedic research. 1991 Sep 1;9(5):641-50.

[2] Bianco P, Robey PG, Simmons PJ. Mesenchymal stem cells: revisiting history, concepts, and assays. Cell stem cell. 2008 Apr 10;2(4):313-9.

[3] Klotz B, Mentrup B, Regensburger M, Zeck S, Schneidereit J, Schupp N, Linden C, Merz C, Ebert R, Jakob F. 1, 25-dihydroxyvitamin D3 treatment delays cellular aging in human mesenchymal stem cells while maintaining their multipotent capacity. PLoS One. 2012 Jan 5;7(1):e29959.

[4] Buttiglieri S, Ruella M, Risso A, Spatola T, Silengo L, Avvedimento EV, Tarella C. The aging effect of chemotherapy on cultured human mesenchymal stem cells. Experimental hematology. 2011 Dec 31;39(12):1171-81.

[5] Yu KR, Lee S, Jung JW, Hong IS, Kim HS, Seo Y, Shin TH, Kang KS. MicroRNA-141-3p plays a role in human mesenchymal stem cell aging by directly targeting ZMPSTE24. J Cell Sci. 2013 Dec 1;126(23):5422-31.

[6] Bianco P, Cao X, Frenette PS, Mao JJ, Robey PG, Simmons PJ, Wang CY. The meaning, the sense and the significance: translating the science of mesenchymal stem cells into medicine. Nature medicine. $2013 \mathrm{Jan}$ $1 ; 19(1): 35-42$. 
[7] Brohlin M, Kingham PJ, Novikova LN, Novikov LN, Wiberg M. Aging effect on neurotrophic activity of human mesenchymal stem cells. PloS one. 2012 Sep 17;7(9):e45052.

[8] Baker N, Boyette LB, Tuan RS. Characterization of bone marrow-derived mesenchymal stem cells in aging. Bone. 2015 Jan 31;70:37-47.

[9] Brunauer R, Laschober G, Fehrer C, Lepperdinger G. Age-associated functional changes of human mesenchymal stem cells. Experimental Gerontology. 2011 Mar 31;46(2):211.

[10] Alrefaei GI, Al-Karim S, Ayuob NN, Ali SS. Does the maternal age affect the mesenchymal stem cell markers and gene expression in the human placenta? What is the evidence?. Tissue and Cell. 2015 Aug 31;47(4):406-19.

[11] Baxter MA, Wynn RF, Jowitt SN, Wraith J, Fairbairn LJ, Bellantuono I. Study of telomere length reveals rapid aging of human marrow stromal cells following in vitro expansion. Stem cells. 2004 Sep 1;22(5):675-82.

[12] Zaher W, Harkness L, Jafari A, Kassem M. An update of human mesenchymal stem cell biology and their clinical uses. Archives of toxicology. 2014 May 1;88(5):1069-82.

[13] Sethe S, Scutt A, Stolzing A. Aging of mesenchymal stem cells. Ageing research reviews. 2006 Feb 28;5(1):91-116.

[14] Dexheimer V, Mueller S, Braatz F, Richter W. Reduced reactivation from dormancy but maintained lineage choice of human mesenchymal stem cells with donor age. PloS one. 2011 Aug 5;6(8):e22980.

[15] Golpanian S, El-Khorazaty J, Mendizabal A, DiFede DL, Suncion VY, Karantalis V, Fishman JE, Ghersin E, Balkan W, Hare JM. Effect of aging on human mesenchymal stem cell therapy in ischemic cardiomyopathy patients. Journal of the American College of Cardiology. 2015 Jan 20;65(2):125-32.

[16] Lee DH, Ng J, Kim SB, Sonn CH, Lee KM, Han SB. Effect of donor age on the proportion of mesenchymal stem cells derived from anterior cruciate ligaments. PloS one. 2015 Mar 2;10(3):e0117224.

[17] Sozou PD, Kirkwood TB. A stochastic model of cell replicative senescence based on telomere shortening, oxidative stress, and somatic mutations in nuclear and mitochondrial DNA. Journal of Theoretical Biology. 2001 Dec 21;213(4):573-86.

[18] Simonsen JL, Rosada C, Serakinci N, Justesen J, Stenderup K, Rattan SI, Jensen TG, Kassem M. Telomerase expression extends the proliferative life-span and maintains the osteogenic potential of human bone marrow stromal cells. Nature biotechnology. 2002 Jun 1;20(6):592-6.

[19] Stenderup K, Justesen J, Clausen C, Kassem M. Aging is associated with decreased maximal life span and accelerated senescence of bone marrow stromal cells. Bone. 2003 Dec 31;33(6):919-26.

[20] Pittenger MF, Mackay AM, Beck SC, Jaiswal RK, Douglas R, Mosca JD, Moorman MA, Simonetti DW, Craig S, Marshak DR. Multilineage potential of adult human mesenchymal stem cells. science. 1999 Apr $2 ; 284(5411): 143-7$.

[21] Schieker M, Pautke C, Reitz K, Hemraj I, Neth P, Mutschler W, Milz S. The use of four-colour immunofluorescence techniques to identify mesenchymal stem cells. Journal of anatomy. 2004 Feb $1 ; 204(2): 133-9$.

[22] Jiang Y, Jahagirdar BN, Reinhardt RL, Schwartz RE, Keene CD, Ortiz-Gonzalez XR, Reyes M, Lenvik T, Lund T, Blackstad M, Du J. Pluripotency of mesenchymal stem cells derived from adult marrow. Nature. 2002 Jul 4;418(6893):41-9. 
[23] Yoon JH, Kang SJ, Oh TK. Algoriphagus locisalis sp. nov., isolated from a marine solar saltern. International journal of systematic and evolutionary microbiology. 2005 Jul 1;55(4):1635-9.

[24] Fehrer C, Lepperdinger G. Mesenchymal stem cell aging. Experimental gerontology. 2005 Dec 31;40(12):926-30.

[25] Infante A, Gago A, de Eguino GR, Calvo-Fernández T, Gómez-Vallejo V, Llop J, Schlangen K, Fullaondo A, Aransay AM, Martín A, Rodríguez CI. Prelamin A accumulation and stress conditions induce impaired Oct-1 activity and autophagy in prematurely aged human mesenchymal stem cell. Aging (Albany NY). 2014 Apr;6(4):264.

[26] Fossett E, Khan WS, Longo UG, Smitham PJ. Effect of age and gender on cell proliferation and cell surface characterization of synovial fat pad derived mesenchymal stem cells. Journal of Orthopaedic Research. 2012 Jul 1;30(7):1013-8.

[27] Fehrer C, Lepperdinger G. Mesenchymal stem cell aging. Experimental gerontology. 2005 Dec 31;40(12):926-30.

[28] Peng L, Ye L, Zhou XD. Mesenchymal stem cells and tooth engineering. International Journal of Oral Science. 2009 Mar;1(1):6.

[29] Choudhery MS, Badowski M, Muise A, Harris DT. Effect of mild heat stress on the proliferative and differentiative ability of human mesenchymal stromal cells. Cytotherapy. 2015 Apr 30;17(4):359-68.

[30] Feng X, Xing J, Feng G, Huang D, Lu X, Liu S, Tan W, Li L, Gu Z. p16 INK4A mediates age-related changes in mesenchymal stem cells derived from human dental pulp through the DNA damage and stress response. Mechanisms of Ageing and Development. 2014 Dec 31;141:46-55.

[31] Aksoy C, Kaya FA, Kuşkonmaz BB, Uçkan D, Severcan F. Structural investigation of donor age effect on human bone marrow mesenchymal stem cells: FTIR spectroscopy and imaging. Age. 2014 Aug 1;36(4):1-7.

[32] Fossett E, Khan WS, Pastides P, Adesida AB. The effects of ageing on proliferation potential, differentiation potential and cell surface characterisation of human mesenchymal stem cells. Curr Stem Cell Res Ther. 2012 Jul;7(4):282-6.

[33] D'Ippolito G, Schiller PC, Ricordi C, Roos BA, Howard GA. Age-related osteogenic potential of mesenchymal stromal stem cells from human vertebral bone marrow. Journal of Bone and Mineral Research. 1999 Jul 1;14(7):1115-22.

[34] Zaim M, Karaman S, Cetin G, Isik S. Donor age and long-term culture affect differentiation and proliferation of human bone marrow mesenchymal stem cells. Annals of Hematology. 2012 Aug 1;91(8):117586.

[35] Méndez-Ferrer S, Michurina TV, Ferraro F, Mazloom AR, MacArthur BD, Lira SA, Scadden DT, Ma'ayan A, Enikolopov GN, Frenette PS. Mesenchymal and haematopoietic stem cells form a unique bone marrow niche. Nature. 2010 Aug 12;466(7308):829-34.

[36] Justesen J, Stenderup K, Kassem MS. [Mesenchymal stem cells. Potential use in cell and gene therapy of bone loss caused by aging and osteoporosis]. Ugeskrift for laeger. 2001 Oct;163(40):5491-5.

[37] Stolzing A, Jones E, McGonagle D, Scutt A. Age-related changes in human bone marrow-derived mesenchymal stem cells: consequences for cell therapies. Mechanisms of ageing and development. $2008 \mathrm{Mar}$ 31;129(3):163-73. 
[38] Bellantuono I, Aldahmash A, Kassem M. Aging of marrow stromal (skeletal) stem cells and their contribution to age-related bone loss. Biochimica et Biophysica Acta (BBA)-Molecular Basis of Disease. 2009 Apr 30;1792(4):364-70.

[39] Trivanović D, Jauković A, Popović B, Krstić J, Mojsilović S, Okić-Djordjević I, Kukolj T, Obradović H, Santibanez JF, Bugarski D. Mesenchymal stem cells of different origin: Comparative evaluation of proliferative capacity, telomere length and pluripotency marker expression. Life Sciences. 2015 Nov 15;141:61-73.

[40] Visweswaran M, Pohl S, Arfuso F, Newsholme P, Dilley R, Pervaiz S, Dharmarajan A. Multi-lineage differentiation of mesenchymal stem cells-To Wnt, or not Wnt. The international journal of biochemistry \& cell biology. 2015 Nov 30;68:139-47.

[41] Defrancesco M, Marksteiner J, Fleischhacker WW, Blasko I. Use of Benzodiazepines in Alzheimer's Disease: A Systematic Review of Literature. Int J Neuropsychopharmacol. 2015;18(10):pyv055.

[42] Shekkeris AS, Jaiswal PK, Khan WS. Clinical applications of mesenchymal stem cells in the treatment of fracture non-union and bone defects. Current stem cell research \& therapy 2012;7(2):127-133

[43] Pastides P, Chimutengwende-Gordon M, Maffulli N, Khan WS. Stem cell therapy for human cartilage defects: a systematic review. Osteoarthritis and Cartilage 2013;21(5):646-654.

[44] Yates EW, Rupani A, Foley GT, Khan WS, Cartmell S, Anand SJ. Ligament tissue engineering and its potential role in anterior cruciate ligament reconstruction. Stem Cells International 2012; :438125. 